\title{
Moving beyond Sport in Primary Physical Education
}

\section{Introduction}

The language and actions of sport are enduring historical features of primary physical education (Jess, McEvilly and Carse, 2016). Whilst this chapter will draw primarily from examples of primary physical education the UK, research which reports from other parts of the world suggest the issues I will raise here are global in nature (Hardman and Marshall, 2006). In England, for example, discourses concerning national sporting success, combating sedentary lifestyles and reducing obesity are now prominent within primary physical education (Griggs, 2015; Petrie, 2016). Indeed, promoting health and long-term adult participation though competence in sport has become an increasing preoccupation within the subject (cf. (DfEE/QCA, 1999; DfE, 2013; Larsson and Redelius, 2008; Svendsen and Svendsen, 2016). For primary aged pupils this involves very distant, long term goals and overlooks their immediate and ongoing understandings of different sports and physical activities (Ward, 2016). These experiences and concerns are not limited to physical education lessons and continue well beyond the school gates. Increasingly, research is drawing attention to the limitations of practices which attempt to reproduce those associated with sport and health within primary physical education (Ward and Quennerstedt, 2014; 2015). Despite claims of equality of opportunity and supporting those willing to make an effort, these practices have been argued to reproduce divisions; between those who enjoy and benefit from their physical education experiences, and those who lose out (Kirk, 2010).

Traditional competitive sport is essentially exclusive in its nature by its delineation of particular bodies, forms of human endeavour and conceptions of success. For those whose competencies are valued by sport, the prevailing practices of physical education permit the accrual of success (Hay and lisahunter, 2006). Conversely, for others physical education can be a limiting, contradictory and sometimes humiliating aspect of their compulsory schooling (Garrett and Wrench, 2007). When physical education reproduces the exclusivity of sport, particular tensions are created for a subject that is tasked with operating within educational values of equality of opportunity, diversity and inclusion. In this chapter I aim to consider some of these tensions and attempt to develop a rationale for the potential offered by reconceptualising the subject as a part of movement culture (Crum, 1993). From this perspective primary physical education lessons become joint spaces of knowledge construction, constituting their own movement cultures. Such a position helps to recognise the many different ways people realise human movement and enables pedagogy to be concerned with the development of critical consumers, and importantly, creators of movement culture (Crum, 1993). In this way the immediate and ongoing understandings of sports which pupils develop both within and beyond the school gates can be recognised, rather than distant, long term adult goals (Ward, 2014).

\section{Problematising performing at sports}

Whether it is delivering test results or offering other forms of cultural capital, all subjects have to earn their place on school curricula (Tinning, 2012). In primary physical education this capital is primarily about developing the required physical fitness, skills and psychological attributes to participate in sports (DfE, 2013). For classroom subjects the nature of this cultural capital has been readily defined through the existence of agreed bodies of knowledge, such as Mathematics, Science and English. For physical education, sport, as a prominent part of cultural life, has become its subject matter (Kirk, 2001). As a result physical education and sport are 
considered one of the same. It is the practices of sport which have thus had a historical and highly influential role in the construction of pedagogical practices in physical education (Petrie, 2016; Svendsen and Svendsen, 2016). Bodily performance obtained through training and the development of character, have consequently come to dominate knowledge construction within the subject (Evans, Rich and Davies, 2009; Walseth, Aartun and Engelsrud, 2015). This convenient home for physiological and psychological discourses has been legitimated by the prevalence of dualistic understandings of knowledge (Quay, 2014; Stolz, 2014). These place the education of the mind as quantifiably more important than physical exertions in the school hall and playground. Despite, contemporary concerns about childhood inactivity and obesity, pupil attainment in the classroom continues to educationally out-trump the cultural capital traditionally offered by sport (Sloan, 2010). The education and development of intellect is consequently left to more serious classroom based subjects (Ennis, 2006; Griggs, 2015; Kirk, 2010). Whilst competencies in sports are considered useful, they have played a historically peripheral supporting role in the broader schooling of pupils (Carr, 1997).

In aiming to achieve these utilitarian ends physical education has drawn predominantly from psychology and biomechanics to analyse both sports and child development (cf. Gallahue and Ozmun, 2006). In doing so, the primary age range has become identified as the window of receptiveness to learn key movement skills (Platovet, 2016). This follows a historical tradition extending back to the early $20^{\text {th }}$ century. In this period physical education consisted of physical training, constituted through drills from Swedish and German gymnastics (Kirk, 2010). Such schools of thought persist within the subject and now argue that by developing individual competency in motor skills pupils develop self-confidence. It is argued that this in turn, increases the likelihood of continued engagement in physical activity (Bryant, Duncan and Birch, 2013; Kalaja, et al., 2011). The first building block in this motor competence has been conceptualised into the accrual of Fundamental Movement Skills (FMS) e.g. catching, throwing, running and jumping (Steps PD, 2004; Gallahue and Donnelly, 2003). These are believed to be the necessary core skills of mainstream sporting activities. Their mastery is therefore, considered a significant determinate of participation in organised sport (Jefferson-Buchanan, 2016; van Beurden, et al., 2003).

Research into this field of primary physical education has aimed to prove causal relationships between pupils completing specialised FMS programmes, their increased motor proficiency and their increased probability in participating in sports (cf. Bremer and Cairney, 2016). The positioning of this research draws from a hierarchical approach to human development (Silcock, 2013). As a result a logical and at first rational, order of stages of physical and psychological milestones is produced and in consequence, the body and mind become separate domains to be trained. However, the many different human meanings derived from participation in sports become reduced into techniques to be mastered and habits of mind to be developed (Stolz, 2014). These reductionist positions, commit what Sicilia-Camacho and Brown (2008) refer to as the 'de-personification and de-subjectification of the learning and teaching process' (p.99). It implies that meaningfulness obtained through participation in these sports is limited when these physical and psychological skills are not re-enacted proficiently. However, meaningfulness can actually be obtained in many different ways, such as being with friends or experiencing your body in a different way beyond everyday routines (Stolz, 2014). Skilfulness is one aspect of this meaningfulness and develops over a prolonged period of time through ongoing experiences. These are not necessarily limited to sport and physical education contexts. Indeed, learning to be skilful is rarely a linear and uniform process (Millar, et al., 2016; Smith, 2016; Tinning, 2015) Therefore, what at first seems a logical and rational approach to physical education, actually ignores the fact that pupils are already in the world and are accruing many different ways of obtaining meaning from physical activities. Reductionist approaches to learning in primary physical education unfortunately act to limit our understanding and responses 
to the often complex and multifaceted development of human beings. Therefore, rationalising the need to practice overarm throwing to 5 year olds because it is essential to play rounders is more problematic than at first it might seem.

Sports skills privilege particular ways of moving which are a function of intersections between gender, class and ethnicity (Azzarito and Solomon, 2005). Normalising human action into FMS ignores the human materialities of learning, the different desires, interests and identities pupils explore in day to day learning (Larsson and Quennerstedt, 2012). In committing to the utilitarian ends of learning FMS, pupils are essentially being disciplined to move in particular gendered, classed and raced ways of moving, in order to fit into similarly socioculturally defined sports (Kirk, 1999). As a consequence certain types of bodies become desirable for particular sports, in particular, mesomorphic, powerful, slim and flexible bodies (Wright, 2000). Bodies not meeting such criteria or not fitting normalised ways of moving can become labelled as unsporting and even considered a risk to poor health (Quennerstedt, 2008; Webb, Quennerstedt and Öhman, 2008; Wrench and Garrett, 2015).

Privileging the subject matter of FMS commits primary pupils to mastering normalised, adult ways of moving. This commitment positions pupils as 'unknowing' and deficient by placing sport skills ahead of pupils' immediate ongoing concerns (Larsson and Quennerstedt, 2012). Whist these concerns might involve developing skilfulness, the latter may actually involve many other dimensions; for example, being skilful at navigating the social challenges of playing a game or adapting rules to make an activity inclusive by matching the sociocultural and environmental context in which it is being played. In tasking itself with preparing young pupils for a very distant adult future, primary physical education actually risks overlooking the many other possible experiences pupils can explore by doing different sports and variations of these sports. Rather, than supporting teachers to 'be with' their pupils during their exploration of ongoing immediate experiences of sports, these reductionist positions on learning and knowledge 'leap in' for and 'leap ahead' of pupils (Quay, 2014). When placed into neo-liberalised economies of curricula delivery by corporate agents such approaches to primary physical education become particularly problematic (Evans and Davies, 2015). These 'bought-in' services often reinforce very narrow ways pupils can come to understand themselves and others by packaging these hierarchical and reductionist practices of sport into physical education curricula (Evans, 2014; Smith, 2013). When placed into schools that are founded upon educational values of equality of opportunity, diversity and inclusion, the presence of these discourses creates serious tensions within the subject (Ward and Quennerstedt, 2014; 2015).

\section{Finding a place for education while participating in sports}

In order to navigate tensions between education and the narrow performativity of sport, government and professional bodies predominantly return to Arnold's (1979) seminal theorising of 'education' within physical education (cf. AfPE, 2008). This is conceptualised as education 'about', 'through' and 'in' movement. However, in exploring this theorising, Whitehead (2013) suggests that Arnold's framework is not as sound as it might initially seem. When claims are made that physical education educates 'about' movement, Whitehead (2013) argues it is 'grandiose' to suggest that such propositional knowledge (Parry, 1998) in all its complexity is effectively "presented, understood and learnt" (p.27). Similarly, Whitehead (2013) voices concerns when considering the claim that the subject can have an illustrative role for wider educational learning or education 'through' movement. This mode of learning essentially reinforces instrumentalism of the subject by reducing it as a means to an end. Whitehead (2013) thus concludes that education 'in' movement provides the strongest platform. However, this is not in Arnold's form as initiation into culturally relevant activities. Rather, it is the aspect of "nurturing individual potential" (p.31) that Whitehead (2013) aims to identify the subject's 
unique contribution to education. Larsson and Quennerstedt (2012) suggest such a position shifts our view towards a phenomenological field of understanding human movement in which humans and their world are considered a unified 'whole'. This approach aims to dissolve boundaries between cognition, emotion, the body and the environment and in doing so overcome the limitations created by reductionist and hierarchical approaches to human movement. Physical education, particularly in the form of 'play', thus becomes located in a unique position of supporting a celebration of our bodily place in the world. Whitehead builds upon this position to create her argument for reconceptualising physical education as 'Physical Literacy' (Whitehead, $2001 ; 2005 ; 2007 ; 2013)$.

\section{Is Physical Literacy a solution?}

In adopting a monist position, physical literacy aims to reunite the separation of mind and body in order to realise the essential value of physical education (Sprake and Walker, 2015; Whitehead, 2013). To achieve this unification, Whitehead (2013) articulates the universal importance of interaction with the environment through movement, as an embodied aspect of our humanity which must never be overlooked or denied. However, Larsson and Quennerstedt (2012) argue such an approach is limited to an exclusively philosophical understanding of human movement. Physical literacy becomes less useful because it simply swaps a dualist position (mind/body) with a monist (unified whole) position. Monist or phenomenological theorising of the body foregrounds humans ahead of sociocultural influence, rather than being "mutually entangled in a simultaneous process" (Larsson and Quennerstedt, 2012; p.294). By doing so "physical literacy does not break free from a notion of a pre- or non-discursive commonly shared body" (Larsson and Quennerstedt, 2012; p.294). Developing physically literate pupils requires the development of competence and efficiency in moving (Whitehead, 2013). As a consequence, the debate spirals back to the tensions created when dominant ways of moving are privileged (Larsson and Quennerstedt, 2012; Barad, 2003; Colebrook, 2000). Research into the consequences of privileging patriarchal ways of moving consistently reveals the dangers created by objectifying particular bodily discourses within physical education practices (Evans, Davies and Rich, 2009). This research helps to shed light upon the role of physical education as a site of 'meaning-making' that has consequences beyond failing to learn how throw overarm or jump. It also helps us to understand physical education as site of "recognition, rejection and despair among teachers, peers and friends" (Evans, Davies and Rich, 2009; p.402).

\section{Navigating the sport-physical education interface}

Working with diverse classes of pupils, providing equality of opportunity whilst also reproducing the tradition practices of competitive sport, produces significant tensions for primary physical education (Ward and Quennerstedt, 2014; 2015). As a result the subject has bumped and bashed pupils into its subject material. Sometimes faithfully reproducing sport practices and at other times rejecting competition and performativity, in favour of child centred educational ideology (Paul, 1996; Quay, 2014). Such a testing relationship has created an interface between physical education and sport that is characterised by a mixture of conflation, pedagogical ambiguity and friction (Nyberg and Larsson, 2014). For example, in the UK the recent iteration of the National Curriculum for Primary Physical Education (NCPPE) calls for schools to teach competitive sports, particularly team games (DfE, 2013). Transforming this subject matter into inclusive learning experiences, for large classes of young rapidly developing pupils, all with varying experiences and abilities creates a substantial challenge to the expertise of non-specialist teachers. Indeed, those in the secondary sector, who are classed as subject specialists, have yet to achieve wide spread success in negotiating this challenge (Kirk, 2010). As a consequence, for some pupils the subject has become a place in which they struggle to negotiate their teachers' construction of what it is to be successful (Hay and lisahunter, 2006; Ward and Quennerstedt, $2014 ; 2015)$. What is required is a means to navigate this contested and ambiguous space 
between sport and physical education, in order to support a more coherent exploration of sport as educational subject matter (Ward, 2014).

Pope (2011) suggests rather than retreating to educational definitions of physical education, the solution will emerge by examining how the interface can help produce mutually supportive pedagogic relationships. Indeed, the subject matter of sport and all the tensions it brings cannot be swept aside. The practices of sport are all pervading within the subject and it is the medium that children experience outside the school gates and bring into their lessons (Kirk, 2010). With this in mind, the recent excitement and growth in academic theorising and research has pointed to the potential of pedagogical models. It is believed that these might be the means to build the supportive relationships between sport and physical education. This debate has championed, for example, the potential of tactical games models, sport education and cooperative education to generate more empowered and engaged learners (cf. Casey, 2014). Unfortunately, their value to primary physical education remains questionable, given the very limited initial teacher education (ITE) and the lack of confidence to teach the subject that has been reported by recent research (Blair and Capel 2011; Harris, Cale, and Musson 2012; Jones and Green, 2015; Tsangaridou, 2014). Pedagogical models require significant expertise that challenges even experienced and specialist teachers of the subject (Harvey, Cushion, and Sammon, 2015; Stolz and Pill, 2016). The picture does not become any brighter when limited and limiting continuing professional learning opportunities in primary physical education are the norm. These are often characterised by quick fix approaches in very short, one-off, workshops delivered by perceived, rather than actual experts (Armour and Duncombe, 2004; Petrie, 2016). Additionally, relying upon sports coaches, who have been subcontracted to deliver physical education in primary schools, and who are not required to demonstrate anything other than basic instructional behaviours, does not seem a realistic expectation. Pedagogical models thus, do not appear to offer a silver bullet to the problematic tensions between educational activity on the one hand, and the performativity of sport on the other.

Tinning (2012) argues no utopian pedagogical practice exists and teaching in physical education will be contingent upon the realities of school facilities and class sizes. Recognition of the complex ecology of pedagogical practices and knowledge construction within the everyday realities of primary physical education are gradually emerging within research literature (cf. Jess, Keay and Carse, 2016; Petrie, 2016; Ward and Quennerstedt, 2014; 2015). These studies aim to challenge 'common sense' or 'folk theories' of learning (Davies and Sumara, 2002; 2003; Hagar and Hokinson, 2009) that appear to accompany the practices of sport. In doing so, such approaches are beginning to highlight the complex interactions between individuals, tasks and environments. These perspectives are revealing what actually might be being learnt other than the outcomes prescribed by the teacher or curriculum (cf. Quennerstedt, Almqvist, Öhman, 2011; Ward and Quennerstedt, 2014; 2015). More organic understandings of knowledge within physical education recognise how pupils and teachers collaboratively negotiate sociocultural meanings within lessons. In consequence, they offer an alternative way to consider the integration of sport and physical education, without relying upon whole scale control of teacher training and professional development practices. In adopting non-linear perspectives of knowledge construction these approaches help to open up the many possibilities that the subject matter of sport can offer school aged pupils. Crum (1993) proposes an example of one such approach by conceptualising physical education and sport as 'movement culture'. In doing so, he offers a potentially useful means to achieve a secure and coherent position of integration for physical education and sport. Rather than focussing on long term adult objectives or specific competencies, Crum (1993) approaches the subject from the possibilities different movement cultures offer knowledge construction. This avoids viewing pupils as objects to be 'done to' or as subordinate to the subject matter of sport. Knowledge from this perspective thus becomes an 
ongoing practical activity that occurs within and across school, family and other sociocultural boundaries.

\section{The possibilities of Movement Culture}

Movement culture is a common umbrella term within the German and Dutch languages which refers to the set of movement actions and interactions created by participants in sport, play, dance, or other fitness activities. Movement culture "refers to the way in which a social group deals with the need and desire for movement beyond labour or maintaining life" and thus encompasses all leisure actions in which the human movement is the 'essence' (Crum 1993, p.341). Kirk (1999; p.65) proposes a revival of the term 'physical culture' to help provide greater historical continuity when analysing the 'embeddedness' of the maintenance, representation and regulation of the body in various cultural practices. However, Kirk's (1999) historical analysis of physical culture tends to privilege relations between social structures and the body, which depersonalises the embodied cultural construction of meanings. Crum (1993) seeks a more organic position in which meanings generated from participating in sports are negotiated collaboratively. Rather than following a logically ordered pattern, these meanings are generated in more ambiguous ways, shaped through the sociocultural contexts in which they occur. Crum (1993) thus rejects the term 'physical' arguing that it has the potential to invoke mind-body dualisms and shifts attention away from the sociocultural construction of movement culture. The creation and maintenance of movement cultures transcends institutional structures such as schools. This helps us to recognise that primary physical education is not an exclusive space for learning. Pupils learn through different ongoing contexts and these experiences are thus brought into and out of physical education (Banks, 1993). When viewed in this way physical education practices become considered as mutual cultural parts of a consistently changing landscape in which "people realise and experience important values, such as recreation, health, adventure, excitement, togetherness, performance, and self-realisation" (Crum, 1993; p.134). People act in different ways to achieve this realisation and these actions are integral to different purposes and motivations. As a result different types of movement cultures can be created, for example, Crum (1992) identifies different 'sports'; elite sport, competitive club sport, recreation sport, fitness sport, risk and adventure sport, lust sport and cosmetic sport.

Crum (1993) argues that as broader cultural landscapes change so does the landscape of movement culture. It is the sociocultural positioning of movement culture that helps physical education to be reflective of the diversity of movement practices, relative to different times and spaces, and integral to changes in cultural norms and values. This postmodern position is developed by Crum (1995) using the concepts of postmodernity, individualisation and rediscovery of the body. He uses these to contextualise the relations between changes in society and cultural implications for the meaning of human movement to school pupils. He argues that a shift towards postmodern values and the "craving for self-realisation, the trend to individualization and the rediscovery of the body....have led to a 'sportification' of society (Crum, 1995; p.1). Within this he suggests there has been an internal differentiation of sport which has shifted a homogeneous sport system to a heterogeneous movement culture (c.f. Green, Smith and Roberts, 2005). Crum (1995) concludes that this change means "movement-cultural sub-systems develop beside each other as different shops with different assortments and different internal rules for different clients, who have different needs and expectations" (p.122). Crum (1995) suggests that such change is fully evident within sport, which acts as a readily accessible "medium for the experience and training of self-determination and self-realisation...irrespective of their sex, age, social class and level of education" (Crum, 1995; p.119). Young people seek and thrive within new kinds of institutions in which authority, and allegiance, must be constantly renegotiated, re-established and earned (Holland and Thomson, 1999). 
The research field has questioned the contribution of physical education in relation to the many utilitarian tasks it has all too readily accepted (Bailey et al., 2009; Kirk, 2010). For example, Thorburn and MacAllister (2013) argue practices framed as 'exercise-as-useful, movement-as-understood and activity-as-enjoyed' "have failed to resource students with enhanced meaningful experiences" (p.463). Crum (1995) similarly suggests that the subject does not necessarily prepare young people to become active creators and consumers of varied forms of physical activity and sports. Movement culture thus becomes a potentially valuable position from which to reconsider subject matter and pedagogy within primary physical education. Crum (1993) tasks physical education to embrace contemporary cultural shifts in sports engagement and participation, encapsulating learning with a "utility value for the movement culture outside the school [maximising] its potential to qualify youngsters for an emancipated, satisfying and lasting participation" (Crum, 1995, p.116). The subject is thus challenged to embrace the wholeness of the ongoing immediacy of pupils' engagement with physical activity. It is this aspect of knowledge construction that focusses our attention upon building rich and emancipating opportunities to explore and create movement cultures. Whilst the normativity of sport practices can define particular movement cultures, these have all too often become the long term aim of physical education (Kirk, 2010; Griggs, and Ward, 2012; Ward, 2012a). Rather than the wholescale rejection of these practices, the position of movement culture encourages us to consider the meeting of subject matter and pupils so that immediacy is not subordinated to long term adult aims. This immediacy can be employed to build towards long term participation; the former being mutually supportive to the latter.

When approached in this way, primary physical education is given a licence to generate its own movement cultures, shaped by the pupils and their own experiences of movement culture. It is here that the teacher becomes a mediator to support critical engagement with these experiences, questioning taken for granted assumptions, in particular the hierarchical and reductionist 'logic' that often dominates subject matter, such as that which accompanies FMS. Calls for primary physical education in the UK to focus on competition can thus be explored in a more critical way (DfE, 2013). For example, there are many different ways competition can be created, beyond the binary models that often dominate physical education (Harvey and O'Donovan, 2013). Viewing sports as movement culture also creates the opportunity to challenge, rethink and recreate physical education experiences through more sophisticated pedagogical relationships with sport.

\section{Learning as action with Movement Culture}

In order to achieve continuity between the individual, social, physical and wider social contexts, Crum (1993) draws from an experiential, cultural position of knowledge construction. One such theory which has many parallels with this position is Dewey and Bentley's (1949/1991) conceptualisation of learning as a transactional process which in turn, provides the basis of Dewey's (1916/1988) understanding of education as 'occupation'. This theorising of education as occupation is not based upon conceptions of occupation as vocational education and training. Rather it conceptualises an experiential understanding of knowledge construction framed by our epistemological engagement with ongoing experiences (Quay, 2014). Dewey (1916/1988) argues education is not a destination but an activity of the present. It is not about preparation for a remote adult future but is tied to human growth rooted in 'a constant reorganising or reconstructing of experience" (Dewey, 1916/1988; p.185). Education via occupation is, therefore, concerned with education for ways of being that are significant for and genuine to young people in the here and now of their immediate existence. These interests can be developed pragmatically through exploration of doing and knowing aligned to an occupation in which knowledge construction occurs through ongoing transactions. According to Dewey and Bentley (1949/1991) transactions have a reciprocal relationship within which an individual acts, that in 
turn lead to changes in the environment which continues to affect the activities of the individual. It is these transactions which characterise experience. Dewey and Bentley (1949/1991) therefore argue that learning should not be regarded as something which exists in the mind but as a collection of experiences or relations in certain events. From this perspective learning is considered as a social construction, an integral part of a physical world which embraces cognitively and emotionally active human beings (Wickman and Östman, 2002). Knowledge becomes a construction which is not only in the mind but is also re-constructed and relived as we experience and live in the world (Beista, 2014).

Moore (2011) contends viewing knowledge in this way changes it from 'what-is', to the realm of 'possibilities'. In other words knowledge shifts from being a noun to an action or 'knowing'. This position avoids issues created by normalising of human movement, such as through FMS. Privileging FMS as subject matter immediately creates an unknowing child (a pupil who does not measure up) or an unknowing child (a pupil who can reproduce these skills). Education as occupation shifts our view to pupils' immediate experiences of subject-matter and to recognising their interests or 'knowings' of movement cultures (Quay, 2014). These become a medium through which the teacher can direct their pedagogical work. There is a danger that such an approach can slip towards more instrumental concerns, by reverting to Arnold's (1979) argument of physical education as initiation into culturally significant activities. However, adopting a transactional position on learning in movement culture avoids such risks because particular forms of movement as certainties or a pre-discursive body devoid of gender, class or race are not privileged.

That is not to say pupils' interests will never reflect dominant social cultural discourses, such as some boys being interested solely in football. Rather than ignoring these preferences, the pedagogical challenge created by movement culture is to utilise them to explore the many possibilities playing football and other games can offer. Crum (1993) does suggest the need to develop 'movement competencies' however, this does not imply the objectification of ways of moving. Rather it aligns with a pragmatic understanding of the development of pupils' capacity to explore different possibilities. These enable them to understand different human concerns and meanings generated by human movement. For example, pupils might learn to complete formal ways of rolling in gymnastics, not as an objectified ends, but as a means to explore what it is to roll in these ways and what possibilities they offer.

\section{Exploring occupations within movement culture}

In order to explore these possibilities, Crum (1993; p.243) identifies four key interdependent strands of learning as a means to guide 'arranging ways of doing and knowing' (Quay, 2014; p.195):

- Technomotor - learning to solve the technical motor problems presented by moving in context.

- Sociomotor - learning to solve the social problems presented by moving and playing with and against others.

- Cognitive/reflective - learning to understand how to become more effective at solving movement problems through understanding the patterns and processes inherently involved.

- Affective - development of a positive bond with exercise, movement, play and sport.

Gagné (2004) asserts whilst there are limitations to distinguishing domains of learning, such as those proposed by Crum (1993), there are three key benefits to doing so. Firstly, this delineation enables the identification of specific curricula areas in which different instructional strategies may be employed, such as, the use of repetitive drills or mini-games to develop technical proficiency (technomotor strand). Secondly, developing learning domains supports an understanding of the relationship between instructional strategies within different curricula areas, 
for example, the use of problem-based learning to develop an understanding of why similar body positions and movements are useful in different contexts (cognitive/reflective stand). Thirdly, they provide a focus for assessing learning outcomes and thus avoid assumptions, for example, that technical proficiency corresponds to comprehension of potential relationships between tactical problems presented by contrasting types of games.

By utilising Bloom's (1956) psychomotor, cognitive and socio-affective domains, Crum (1993) places learning processes at the forefront of the subject. Crum (1993) argues there is a balancing act to be achieved here. Balancing the risk of decontextualising learning by keeping physical education at a safe distance from competitive sport to focus attention on learning within these domains, with maintaining elements of fun, celebration, competition and achievement, which intra and inter school sport can offer. The interdependent strands of learning serve to provide a useful guide to the possible arrangement of knowing and doing in order to support pupils in becoming critical consumers and creators of movement cultures. By not objectifying skills and activities the door is opened to the exploration of the social making of movement culture. In particular, an appreciation that rules can and should be changed to support learning and enjoyment. By doing so, pupils are empowered to change the conventions and rules which govern different sports and physical activities to support their own particular concerns and pursuits (Crum, 1993). Crum (1995) suggests that in this way learning becomes focussed upon the process of solving movement problems in different contexts. Subject-matter thus becomes positioned within pupils' immediate experiences, rather than as a distant aim of adult participation.

Categorising learning processes provides the teacher with a framework to generate an overview of how particular curricula subject matter can generate different learning possibilities. In turn, a robust rationale for selection of instructional strategies and assessment outcomes can then be generated. The delineation of learning strands, however, does not transfer into the physical education lesson. The interdependent nature of learning domains means that the use of particular instructional tools or the focus on particular learning processes will inherently demand learning from different domains. For example, when teaching gymnastics, Crum's (1993) stands of learning may support a teacher in deciding to focus upon technomotor and affective learning processes. The teacher may decide, therefore, to use a particular pedagogical approach to support pupils in the achievement of learning outcomes connected to coaching, team managing and officiating. Preparing for and competing in a class competition in gymnastics will also implicitly demand, for example, understanding the sequencing of actions. This may be developed and performed in groups and would involve sociomotor and cognitive/reflective learning.

\section{Putting a theory of practice to work}

Tables 1 and 2 provide an example of the potential of Crum's learning strands to support the exploration of some traditional subject matter in primary physical education (Ward, 2014). Contrasting activity areas have been chosen to demonstrate the usefulness of such an approach, by drawing from Best's (1978) 'purposive' and 'aesthetic' sports help to reveal underlying possibilities for their exploration. Purposive sports include competitive games and athletic activities (Davis, 2007). These activities have clearly defined objectives, however, the manner in which these are achieved within the rules is unimportant. In contrast, aesthetic sports such as gymnastics, have aims in which the means to achieve these aims are implicit and cannot be distinguished (Best, 1978). The frameworks presented utilise Crum's (1993) stands of learning and an additional axis of developmental phases. The latter axis is drawn from motor skill theorising of child development (c.f. Gallahue and Donnelly, 2003) in order to place the potential of this position into prevailing medicalised ways of viewing child development. They are used with the proviso that not all children develop according to a universal time frame and merely to show progression in complexity. 
Table 1 exemplifies the possible direction experiences may take when analysing the subject matter of games. A similar process has been completed in Table 2 for gymnastic activities. Both aim to exemplify the value each learning strand contributes to mapping a breadth of potential learning possibilities. The games framework in Table 1 is based upon an analysis of the 'purposes' of different categories of games (defined by their rules and equipment) developed by Ward and Griggs (2011) and Ward (2012b) which utilises Principles of Play, Tactical Problems, Tactical Solutions, On-the-ball and Off-the-ball skills as a means to identify the movement problems rules in games create. These may take the form of broad thematic problems, such as maintaining possession using different equipment and rules, or developed into more specialised specialist sport centred movement problems, such as penetrating and scoring in netball. Pupils can also be encouraged to create their own games, either within these traditional problems or by encouraging them to create their own movement problems (Hastie, 2010). The analysis of gymnastic activities in Table 2 approaches the subject matter where movement is considered the purpose of the activity. There is potential here to layer this exploration into movement problems such as Newlove and Dalby's, (2005) exploration of Laban's analysis of movement (cf. Ward, 2014). These movement problems can be investigated together within the context of movement themes such as travelling, balancing and flight (cf. Malmber, 2003; Werner, 2004 ). These movement themes become important because they are a consequence of the aesthetic nature of gymnastics (cf. Ward, 2014). Both tables are not exhaustive and serve only to represent examples of the breadth of learning outcomes which can be developed from the position of movement culture.

It is the analysis of subject matter in relation to its pedagogical possibilities and then transformation into lesson material that enables learning as 'occupation' within movement culture to become realised. The learning strands act as portable structures to support teachers in realising the many different possibilities exploring sports can offer. This helps to dissolve the dominance and exclusivity of traditional competitive sports. Analysing sports from the perspective of movement culture takes this exclusivity and creates a purposeful licence to change the form of sports. By exploring the many possibilities sport offer and critiquing taken for granted practices, the nature of subject matter being explored can be conjoined with pupils' own knowings. In this wat primary physical education becomes about human growth, rather than being dominated by chronologically and socioculturally normalised ways of moving.

\section{Summary}

The terrain between sport and physical education is complex and contested. Within this terrain educational values of diversity, inclusion and equality of opportunity clash with the exclusivity and normalising practices of sport. As the subject matter of primary physical education, sport has come to dominate the subject, in particular, the notion that pupils require FMS in order to access movement culture. These types of approaches to the subject are based upon hierarchical and reductionist thinking about developing children and sport as subject matter. In adopting such perspectives the sociocultural complexity which creates our diverse engagement in physical activities is overlooked. This results in the favouring of privileged ways of moving. Attempts have been made to widen our view of the educational value of primary physical education through the theorising of physical literacy. However, these attempts continue to legitimate the reproduction of raced, classed and gendered ways of moving. In this chapter I have examined an alternative to such ways of thinking that conceptualises physical education within movement culture. I have explored the potential of this position to secure a coherent position of integration for physical education and sport. This exploration has revealed how movement culture draws from Deweydian thinking about knowledge construction. It also encourages us to consider learning in primary physical education in a similar way to learning within an occupation. This practical embodied approach to ongoing knowledge construction provides us with a 
framework of learning strands to support the analysis of the potential of subject matter for learning. I have applied this framework to some traditional primary physical education subject matter. In doing so I have attempted to illustrate how such an approach can help our insight into the many different directions of experiences that can be taken within primary physical education. 
Table 1. Technomotor, Sociomotor, Reflective/Cognitive and Affective Learning Outcomes in Games (Ward, 2014)

\begin{tabular}{|c|c|c|c|c|}
\hline \multirow{2}{*}{ Strands of Learning: } & \multicolumn{4}{|c|}{ Stages of Building Technomotor, Sociomotor, Cognitive/Reflective and Affective Development. } \\
\hline & Play and Early Years & Fundamental Movement Phase & Specialised Movement Phase & Specialised Activity Phase \\
\hline $\begin{array}{l}\text { Technomotor } \\
\text { Learning to solve the technical motor } \\
\text { problems presented by moving in } \\
\text { context. }\end{array}$ & $\begin{array}{l}\text { Explore simple actions and } \\
\text { combinations of actions themed } \\
\text { around Travelling (off-the-ball), } \\
\text { Sending (on-the-ball) } \\
\text { Travelling (on-the-ball) } \\
\text { Receiving (on-the-ball), Passing } \\
\text { (on-the-ball). Work towards being } \\
\text { in control of implements and } \\
\text { objects through developing co- } \\
\text { ordination. }\end{array}$ & $\begin{array}{l}\text { Develop experiences of Travelling (off-the-ball), } \\
\text { Sending (on-the-ball), Travelling (on-the-ball), } \\
\text { Receiving (on-the-ball) and Passing (on-the- } \\
\text { ball). Understand the reciprocal nature of game } \\
\text { skills and how timing affects desired outcomes. } \\
\text { Use these skills within simple games which } \\
\text { provide the time and space for the regular and } \\
\text { consistent opportunities for the skills to be } \\
\text { executed with a recognised tactical purpose. }\end{array}$ & $\begin{array}{l}\text { Refine and combine actions to develop control, co- } \\
\text { ordination and fluency in a range of skills. Execute these } \\
\text { skills appropriately and effectively in relation to the } \\
\text { created games. Create contexts which provide regular and } \\
\text { consistent opportunities for the skills to be executed with } \\
\text { a specific tactical purpose and agreed outcome. }\end{array}$ & $\begin{array}{l}\text { Execute combinations of specialised skills related to } \\
\text { specific sporting versions of games with fluency and } \\
\text { consistent accuracy. Connect the execution of these } \\
\text { skills with timing and effective decision making to } \\
\text { reflect specific tactical solutions within particular phases } \\
\text { of play. }\end{array}$ \\
\hline $\begin{array}{l}\text { Sociomotor } \\
\text { Learning to solve the social problems } \\
\text { presented by moving and playing } \\
\text { with and against others. }\end{array}$ & $\begin{array}{l}\text { Work with others to develop } \\
\text { considerate and safe behaviour } \\
\text { when working with games } \\
\text { equipment such as, taking turns, } \\
\text { Creating, understanding and } \\
\text { abiding by simple rules. }\end{array}$ & $\begin{array}{l}\text { Recognise how abiding by agreed rules and fair } \\
\text { play contribute to enjoyable game play. } \\
\text { Compare and contrast the social demands of } \\
\text { individual and small team games. Explore } \\
\text { simple solutions to these social challenges. } \\
\text { Recognise the importance of team affiliation and } \\
\text { how including and supporting others can aid its } \\
\text { creation. }\end{array}$ & $\begin{array}{l}\text { Understand how etiquette contributes to an enjoyable } \\
\text { competitive environment and how adopting an officiating } \\
\text { role can support fair and enjoyable game play. } \\
\text { Recognise how perspective and context can support the } \\
\text { need for a balance between competitive results and } \\
\text { learning and progression. Recognise the importance of all } \\
\text { team members in solving tactical problems created by } \\
\text { team games and understand the social-emotional } \\
\text { challenges created by competitive game play. Explore } \\
\text { different possible outcomes and directions games can } \\
\text { create. Explore the role of positive feedback, recognising } \\
\text { individual strengths and weaknesses and motivational } \\
\text { states can help these challenges to be overcome. Learn } \\
\text { how to provide appropriate feedback to support more } \\
\text { proficient movement and tactical play when practicing } \\
\text { and playing. Understand the contribution adopting } \\
\text { officiating, coaching, statistician and competition } \\
\text { manager roles can play in supporting game play and } \\
\text { player development. }\end{array}$ & $\begin{array}{l}\text { Understand how empathy, focussing on positive efforts } \\
\text { and strategic thinking are required to create and support } \\
\text { team affiliation. Consider the different roles required } \\
\text { within teams such as motivator, ideas person and team } \\
\text { player. Work with peers to create games and/or adjust } \\
\text { rules and conditions to support the execution of specific } \\
\text { skills to reach particular tactical solutions. Create and } \\
\text { adopt different formal roles such as official, coach, } \\
\text { captain, manager, competition manager to support } \\
\text { enjoyable and competitive play. Respect the efforts and } \\
\text { decisions of those adopting these roles. Explore different } \\
\text { forms of competition and the consequences of their } \\
\text { outcomes. Work appropriately and with independence } \\
\text { to develop individual and team proficiency. }\end{array}$ \\
\hline
\end{tabular}


Table 1 (continued) Technomotor, Sociomotor, Reflective/Cognitive and Affective Learning Outcomes in Games (Ward, 2014)

\section{Cognitive/Reflective}

Learning to understand how to become more effective at solving movement problems through understanding the patterns an processes inherently involved.

\section{Affective}

Developing of a positive bond with exercise, movement, play and sport.
Explore different properties of equipment and the relationship between movements and their effect on this equipment. Develop an understanding of personal space and recognis and utilise empty space. Recognise how different movements create differen demands on the body.

Develop confidence and enjoyment of exploring the control of various pieces of equipment which may be used in game play. Develop selfmanaged and independent engagement with created activities.
Recognise the relationship between

rechnomotor movements and successful execution. Reflect upon "effectiveness" within the context - what can be the logics of practice (e.g. social inclusion, effective techical and tactical play)

Develop an understanding of the benefits of consistency in conditions when practicing to become more proficient at particular skills.

Recognise the relationship between rules and equipment and the creation of tactical problen Recognising basic tactical solutions to these tactical problems.

Recognise the connection between on-the-ball and off-the-ball skills and the decisions tha have to be made. Recognise that decision making and skilfulness are not limited to those in direct contact with the ball.

Recognise the physical fitness and technomotor demands of different skills.

\section{Develop independence, confidence and} enjoyment of exploring particular skills within different game contexts. Negotiate outcomes and persevere to achieve these in different games.
Understand and recognise how rules and equipment create categories of games based upon the tactical problems they represent players.

Work as an individual and with others to explore the relationships between on-the-ball and off-the-ball and skills and their conection to particular tactical solution to particular tactical problems.

Recognise similarities and differences between on-theball skills, off-the-ball skills and tactical solutions in games with similar and contrasting tactical problems.

Recognise how rules and equipment can be altered to create games which represent phases of game play and facilitate development of skill execution and appropriate, effective decision making.

Reflect upon the reasoning behind decisions made during game play and develop an understanding the cycle of information processing, particularly the role of selective attention in making quick decisions.

Recognise how to observe skill execution and recognise strengths and areas to develop. Recognise how the latter can be developed in isolated and game-related practices. Identify the fitness requirements of different skills and recognise a connection with other activity areas. Reflect upon personal strengths and employ this information make decisions over what and how to practice, by devising fitness activities, skill practices and simple games. Recognise how playing games can contribute to personal health.

Contribute to team affiliation within games learning and commit to achieve negotiated outcomes from learning tasks. Take ownership of small games, being prepared to adopt non-playing and playing roles to support play.

Consider the different reasons and motivations people might have when playing games. Reflect upon your own and if they vary between context.

Work independently and with others to develop personal strengths and areas of development through individualised practices and games.

Explore strategies which can be used to support the management of emotions when performing. Identify formal and informal opportunities within the local environment and community to engage in game play. Reflect upon factors which affect personal motivations to
Analyse and demonstrate an understanding of the

relationships between particular on-the-ball and off-the-ball and skills and their connection with a combination of tactica context of specific sporting forms of games.

Understand similarities and differences between on-the-ball skills, off-the-ball skills and tactical solutions in games with similar and contrasting tactical problems.

Understand how rules and equipment can be altered to create games which represent phases of game play and facilitate development of skill execution and appropriate, effective decision making.

Analyse decisions made during game play through an understanding of information processing and selective attention.

Employ simple frame-works for analysing the execution of on-the-ball and off-the-ball skills to evaluate their effectiveness. Reflect upon personal strengths, weaknesses and motivations, using this information to devise practices to help develop physical fitness, technomotor competence and/or decision making. Understand how skills, fitness an the social dimensions of playing games can contribute to personal health.

\section{Demonstrate perseverance in practicing to develop} individual physical fitness, technomotor and decisio making competencies

Demonstrate a desire to work independently and take ownership in groups in the structuring and maintenance of an intra-class event. Fulfil playing and non-playing roles with commitment to ensure the successful completion of class event.

Reflect upon personal experiences of game play within the community and analyse the structures involved in this provision. Research some of the different motivations and concerns people have when joining teams or playing games. Explore how potential barriers to participation and enjoyment may be overcome. 
Table 2. Technomotor, Sociomotor, Reflective/Cognitive and Affective Learning Outcomes in Gymnastics (Ward, 2014)

\begin{tabular}{|c|c|c|c|c|}
\hline \multirow{2}{*}{ Strands of Learning: } & \multicolumn{4}{|c|}{ Stages of Building Technomotor, Sociomotor, Cognitive/Reflective and Affective Development. } \\
\hline & Early Years Play & $\begin{array}{c}\text { Fundamental Movement } \\
\text { Skills Phase }\end{array}$ & Specialised Movement Phase & Specialised Activity Phase \\
\hline $\begin{array}{l}\text { Technomotor } \\
\text { Learning to solve the technical } \\
\text { motor problems presented by } \\
\text { moving in context. }\end{array}$ & $\begin{array}{l}\text { Explore simple actions } \\
\text { and combinations of } \\
\text { actions which enable the } \\
\text { exploration of the key } \\
\text { movement themes. }\end{array}$ & $\begin{array}{l}\text { Explore space around the self and } \\
\text { apparatus to develop and combine actions. } \\
\text { Explore movement sentences that attempt } \\
\text { to reflect movement themes and } \\
\text { compositional concepts of directions, } \\
\text { levels and speeds. Develop an } \\
\text { understanding of criteria for judging the } \\
\text { quality of actions. }\end{array}$ & $\begin{array}{l}\text { Refine and combine actions to develop more specialised gymnastic } \\
\text { actions; part of or whole actions, including e.g. partial or full } \\
\text { inversion of the body. Demonstrate movement sentences which } \\
\text { explore space around the self, others and apparatus to show a } \\
\text { breadth of understanding across the movement themes and } \\
\text { compositional concepts. Exhibit varied changes in body tension, } \\
\text { control, co-ordination and fluidity of movement. }\end{array}$ & $\begin{array}{l}\text { Develop and execute combinations of specialised skills which } \\
\text { demonstrate a breadth and depth of understanding across the } \\
\text { movement themes and compositional concepts. Exhibit } \\
\text { precision in varied changes in body tension, fluidity, control, } \\
\text { co-ordination. }\end{array}$ \\
\hline $\begin{array}{l}\text { Sociomotor } \\
\text { Learning to solve the social } \\
\text { problems presented by moving and } \\
\text { playing with and against others. }\end{array}$ & $\begin{array}{l}\text { Exhibit considerate and } \\
\text { safe behaviour when } \\
\text { working with others } \\
\text { within a gymnastic } \\
\text { environment. Contribute } \\
\text { to agreed working } \\
\text { conditions; abide to these } \\
\text { codes of conduct. Share } \\
\text { movement ideas with } \\
\text { others and support others } \\
\text { in their enjoyment of } \\
\text { gymnastic movement. } \\
\end{array}$ & $\begin{array}{l}\text { Work individually and in small groups to } \\
\text { explore solutions to simple movement } \\
\text { problems. Apply some criteria for quality. } \\
\text { Develop an understanding of the roles } \\
\text { listening and speaking play in supporting } \\
\text { communication in the exchange and } \\
\text { development of ideas. Work with others to } \\
\text { handle and share apparatus safely and } \\
\text { considerately. }\end{array}$ & $\begin{array}{l}\text { Work individually and with others to create and solve movement } \\
\text { problems. Demonstrate an understanding of how to work } \\
\text { effectively with others to share and build upon ideas, selecting and } \\
\text { developing appropriate solutions which match individual abilities. } \\
\text { Develop an understanding of how to provide feedback to support } \\
\text { the development of movement quality. Understand and adopt } \\
\text { different roles within an intra class project such as a display to } \\
\text { other year groups. Develop an understanding of how movement } \\
\text { solutions and the immediate environment can be adjusted to } \\
\text { support safety, learning and enjoyment. }\end{array}$ & $\begin{array}{l}\text { Work with peers to create and adjust conditions which support } \\
\text { safety, learning and enjoyment and the demonstration of } \\
\text { solutions to complex movement problems. Demonstrate } \\
\text { effectiveness in exchanging and developing ideas which } \\
\text { support group cohesion and that lead to inclusive and effective } \\
\text { movement solutions. Adopt coaching and officiating roles to } \\
\text { support intra-class activities which promote more proficient } \\
\text { and complex movement. }\end{array}$ \\
\hline $\begin{array}{l}\text { Cognitive/Reflective } \\
\text { Learning to understand how to } \\
\text { become more effective at solving } \\
\text { movement problems through } \\
\text { understanding the patterns and } \\
\text { processes inherently involved. }\end{array}$ & $\begin{array}{l}\text { Recognise differences } \\
\text { between movement } \\
\text { themes and begin to } \\
\text { associate recognised terms } \\
\text { to describe these } \\
\text { movements. Recognise } \\
\text { how movements can be } \\
\text { sequenced to enable the } \\
\text { safe exploration of the } \\
\text { movement themes. } \\
\text { Reflect upon the } \\
\text { challenges different types } \\
\text { of movement present. }\end{array}$ & $\begin{array}{l}\text { Begin to understand the differences } \\
\text { between movement themes and connect } \\
\text { key vocabulary to movements within them. } \\
\text { Build a working knowledge of quality by } \\
\text { reviewing you own and others' work. } \\
\text { Recognise how the sequencing of } \\
\text { movements can enable the fluid } \\
\text { exploration of the movement themes. } \\
\text { Understand how body tension and } \\
\text { momentum can be used to create different } \\
\text { body shapes and qualities of movement. } \\
\text { Recognise the role of different types of } \\
\text { fitness in supporting the body in exploring } \\
\text { gymnastic movement and enabling the safe } \\
\text { lifting and carrying of apparatus. }\end{array}$ & $\begin{array}{l}\text { Develop an understanding of the key features of particular body } \\
\text { positions and movements which enable fluid and aesthetic } \\
\text { movement within and between the movement themes. Understand } \\
\text { the decisions required to develop movement sentences which } \\
\text { explore the movement themes and compositional concepts. Begin } \\
\text { to employ this understanding to improve personal and peer } \\
\text { movement proficiency. Understand the key components of } \\
\text { physical fitness which support the body in exploring gymnastic } \\
\text { movement and enable the safe lifting and carrying of apparatus. } \\
\text { Recognise the connections between the movement requirements } \\
\text { within gymnastics and other activity areas. Recognise the } \\
\text { potential gymnastic movement can contribute to health. }\end{array}$ & $\begin{array}{l}\text { Apply understanding of body positions and movements that } \\
\text { demonstrate fluid and aesthetic movement to support the } \\
\text { quality of movement of the self and others. Reflect upon and } \\
\text { explore the decisions required to develop complex movement } \\
\text { sentences which explore different movement themes and } \\
\text { compositional concepts. Design a set of criteria from which to } \\
\text { judge performed sequences. Understand the connections } \\
\text { between the movement requirements within gymnastics and } \\
\text { other activity areas. Understand how gymnastic movement } \\
\text { can contribute to wellbeing. }\end{array}$ \\
\hline $\begin{array}{l}\text { Affective } \\
\text { Developing of a positive bond with } \\
\text { exercise, movement, play and } \\
\text { sport. }\end{array}$ & $\begin{array}{l}\text { Develop confidence and } \\
\text { enjoyment of exploring } \\
\text { movement individually } \\
\text { and with others. Share } \\
\text { movement ideas through } \\
\text { demonstration and peer } \\
\text { teaching. }\end{array}$ & $\begin{array}{l}\text { Develop confidence and enjoyment from } \\
\text { exploring space around the self, apparatus } \\
\text { and others. Rise to the challenge of } \\
\text { solving and refining movement problems, } \\
\text { taking pride in the demonstration of } \\
\text { solutions reached. }\end{array}$ & $\begin{array}{l}\text { Demonstrate perseverance in engaging with the creation of } \\
\text { movement sentences individually and with others. Take } \\
\text { ownership and care of individual and group movement solutions } \\
\text { and perform these solutions to others. Recognise how learning } \\
\text { within gymnastics can be applied to other environments within the } \\
\text { local community. Reflect upon factors which affect motivations } \\
\text { to engage with these opportunities. }\end{array}$ & $\begin{array}{l}\text { Demonstrate a desire to work independently and in groups to } \\
\text { develop movement sentences for an intra-class event. Adopt } \\
\text { different roles in this event to help its smooth running. Perform } \\
\text { work in front of larger groups and identify where in the local } \\
\text { community learning and participation can be continued. } \\
\text { Reflect upon personal experiences of gymnastics within the } \\
\text { community, analysing the strengths and weaknesses of } \\
\text { structures and involved in this provision. Explore how } \\
\text { potential barriers to participation and enjoyment may be } \\
\text { overcome. }\end{array}$ \\
\hline
\end{tabular}




\section{References}

Association for Physical Education (AfPE) (2008) A manifesto for a world class system of physical education, Reading: AfPE.

Armour, K. and Duncombe, R. (2004) Teachers' continuing professional development in primary physical education: Lessons from present and past to inform the future. Physical Education and Sport Pedagogy, 9(1), 3-22.

Arnold, P. J. (1979) Meaning in movement, sport and physical education. London: Heinemann.

Azzarito, L. and Solomon, M. (2005) A reconceptualization of physical education: The intersection of gender/race/social class. Sport, Education and Society, 10(1), 25-47.

Bailey, R., Armour, K. Kirk, D., Jess, M. Pickup, I. and Sandford, R. (2009) The educational benefits claimed for physical education and school sport: An academic review. Research Papers in Education, 24(1), 1-27.

Banks, J. (1993) The canon debate, knowledge construction and multicultural education. Educational Researcher, 22(5), 4-14.

Barad, K. (2003) Posthumanist performativity: Toward and understanding of how matter comes to matter. Signs: Journal of Women in Culture and Society, 28(3), 801-831.

Best, D. (1978) Philosophy and human movement. London: Allen and Unwin.

Biesta, G. (2014) Pragmatising the curriculum: bridging the knowledge back into curriculum conversation but via pragmatism. The Curriculum Journal, 25(1), 29-49

Blair, R. and Capel, S. (2011) Primary physical education, coaches and continuing professional development. Sport, Education and Society, 16(4), 485-505.

Bloom, B. (Ed.) (1956) Taxonomy of educational objectives, the classification of educational goals: Handbook 1: cognitive domain. New York: McKay.

Bremer, E. and Cairney, J. (2016) Fundamental movement skills and health-related outcomes a narrative review of longitudinal and intervention studies targeting typically developing children. American Journal of Lifestyle Medicine, i-first article, available at:

http://dx.doi: 10.1177/1559827616640196

Bryant, E., Duncan, M. and Birch, S. (2013) Fundamental movement skills and weight status in British primary school children. European Journal of Sport Science, 14(7):730-6.

Carr, D. (1997) Physical education and value diversity: a response to Andrew Reid. European Physical Education Review, 3(2), 195-205.

Casey, A. (2014) Models-based practice: great white hope or white elephant? Physical Education and Sport Pedagogy, 19(1), 18-34.

Colebrook, C. (2000) From radical representations to corporeal becomings: The feminist philosophy of Lloyd, Grosz, and Gatens, Reconfiguring Feminism and Philosophy, 15(2), 76-93.

Crum, B. (1992) Over de Versporting van de Samenleving, Haarlem: De Vrieseborch. 
Crum, B. (1993) Conventional thought and practice in physical education: Problems of teaching and implications for change. Quest 45, 339-356.

Crum, B. (1995) Changes in movement culture: A challenge for sport pedagogy, In: G. DollTepper and W. Brettschneider (Eds) Physical education and sport: changes and challenges, Aachen: Meyer and Meyer, 114-131.

Davis, B. and Sumara, D. (2002) Why Aren't They Getting This? Working through the regressive myths of constructivist pedagogy. Teaching Education, 14(2), 123-140.

Davis, B. and Sumara, D. (2003) Constructivist discourses and the field of education: Problems and possibilities. Educational Theory, 52(4), 409-428.

Davis, P. (2007) A consideration of the normative status of skill in the purposive sports. Sport, Ethics and Philosophy, 1(1), 22-32.

Department for Education (DfE) (2013) The National Curriculum in England: Key Stages 1 and 2 Framework Document. London: DfE.

Department for Education and Employment/Qualifications and Curriculum Authority (DfEE/QCA) (1999) The National Curriculum in England; Physical Education, London:

Dewey, J. (1916/1988) Democracy and education, In: J. A. Boydston (Ed.) John Dewey: The Middle Works, Vol. 9, Carbondale: University of Southern Illinois Press.

Dewey, J. and Bentley, A.F (1949/1991) Knowing and the Known, In J. A. Boydston (Ed.) John Dewey: The Later Works 1925-1953, Vol. 16, Carbondale, IL: Southern Illinois University Press.

Ennis, C. (2006) Curriculum: Forming and reshaping the vision of physical education in a high need, low demand world of schools. Quest, 58, 41-59.

Evans, J. (2014) Equity and Inclusion in Physical Education PLC, European Physical Education Review, 20(3), 319--334.

Evans, J. and Davies, B. (2015) Neoliberal freedoms, privatisation and the future of physical education. Sport, Education and Society, 20 (1), 10-26.

Evans, J., Davies, B., and Rich, E. (2009) The body made flesh: Embodied learning and the corporeal device. British Journal of Sociology of Education, 30, 381-406.

Gagne', R. M. (2004) Domains of learning, In: R. M. Gagne', L.J. Briggs, K. Golas and J. Keller (Eds) Principles of instructional design (5th edn), Independence, Kentucky: Wadsworth Publishing,

87-105.

Gallahue, D. and Donnelly, F. (2003) Development physical education for all children, $4^{\text {th }}$ edition. Champaign, Il: Human Kinetics

Gallahue, D. and Ozmun, J. (2006) Understanding motor development: infants, children, adolescents, adults. Boston: McGraw Hill. 
Garrett, R. and A. Wrench (2008) Connections pedagogy and alternative possibilities in primary physical education. Sport, Education and Society, 13(1), 39-60.

Green, K., Smith, A. and Roberts, K. (2005) Young people and lifelong participation in sport and physical activity: a sociological perspective on contemporary physical education programmes in England and Wales. Leisure studies, 24(1), 27-43.

Griggs, G. (2015) Understanding Primary Physical Education. Routledge: Abingdon.

Griggs, G. and Ward, G. (2012) Physical Education in the UK: disconnections and connections. Curriculum Journal, 23(2), 207-229.

Hagar, P. and Hodkinson, P. (2009) Moving beyond the metaphor of transfer of learning. British Educational Research Journal, 35(4), 619-638.

Hardman, K. and Marshall. J. (2009) Second World-wide Survey of School Physical Education. Final Report. Berlin, HandP Druck/ICSSPE.

Harris, J., Cale, L. and Musson, H. (2012) The predicament of primary physical education: a consequence of 'insufficient' ITT and 'ineffective' CPD? Physical Education and Sport Pedagogy, 17(4), 361-381.

Hay, P. and lisahunter (2006) 'Please Mr Hay, what are my poss(abilities)?': legitimation of ability through physical education practices. Sport, Education and Society, 11:3, 293-310.

Harvey, S., Cushion, C. and Sammon, P. (2015) Dilemmas faced by pre-service teachers when learning about and implementing a game-centred approach. European Physical Education Review, 21(2), 238-256.

Harvey, S., and O'Donovan, T.M. (2013) Pre-service physical education teachers' beliefs about competition in physical education. Sport, Education \& Society, 18 (6), 767-787

Hastie, P. (2010) Student Designed Games: Strategies for promoting creativity, co-operation and skill development, Champaign: Human Kinetics.

Holland, J. and Thomson, R. (1999) Respect-youth values: identity, diversity and social change. ESRC Children 5-16 Research Programme Briefing, London: ESRC.

Jefferson-Buchanan, R. (2016) Traces of discourses and governmentality within the content and implementation of the Western Australian Fundamental Movement Skills programme (STEPS Professional Development), Education 3-13, 44(5), 525-536.

Jess, M., Keay, J. Carse, N. (2016) Primary physical education: a complex learning journey for children and teachers. Sport, Education and Society, 21(7), 1018-1035.

Jess, M. McEvilly, N. and Carse, N. (2016) Moving primary physical education forward: start at the beginning. Education 3-13, i-first article, available at: :

http://dx.doi:10.1080/03004279.2016.1155072.

Jones, L. and Green, K. (2015) Who teaches primary physical education? 
Change and transformation through the eyes of subject leaders. Sport, Education and Society, ifirst article, available at: http://dx.doi.org/10.1080/13573322.2015.1061987

Kalaja, S., Jaakkola, T., Liukkonen, J., \& Digelidis, N. (2011). Development of junior high school students' fundamental movement skills and physical activity in a naturalistic physical education setting. Physical Education and Sports Pedagogy, 17, 411-428.

Kirk, D. (1999) Physical culture, physical education and relational analysis. Sport Education and Society, 4(1), 63-73.

Kirk, D. (2001) Schooling bodies through physical education: Insights from social epistemology and curriculum history. Studies in Philosophy and Education, 20, 475-487.

Kirk, D. (2010) Physical Education Futures. London: Routledge.

Larsson, H. and Quennerstedt, M. (2012) Understanding movement: A sociocultural approach to exploring moving humans. Quest, 64, 283-298.

Larsson, H. and Redelius, K. (2008) Swedish physical education research questioned-current situation and future directions. Physical Education and Sport Pedagogy, 13(4), 381-398.

Malmber, E. (2003) Kidnastics: A child centred approach to teaching gymnastics. Leeds: Human Kinetics.

Millar, A., Christensen, E., Eather, N., Gray, S., Sproule, J., Keay, J. and Lubans, D. (2016) Can physical education and physical activity outcomes be developed simultaneously using a gamecentered approach? European Physical Education Review, 22(11), 113-133.

Moore, R. (2011) Towards a sociology of truth. London: Continuum.

Newlove, J. and Dalby, J. (2005) Laban for all. London: Nick Hern Books.

Nyberg, G. and Larsson, H. (2014) Exploring 'what' to learn in physical education. Physical Education and Sport Pedagogy, 19(2), 123-135.

Paul, J. (1996) Centuries of change: Movement's many faces. Quest, 48(4) 531-545.

Petrie, K. (2016) Architectures of practice: constraining or enabling PE in primary schools, Education 3-13, 44(5), 537-546.

Platovet, (2016) Four week of goal-directed learning in primary physical education classes. Perceptual and Motor Skills, i-first article, available at:

http://dx.doi: 10.1177/0031512516648729

Pope, C. (2011) The physical education and sport interface: Models, maxims and maelstrom. European Physical Education Review, 17(3), 273-285.

Quay, J. (2014) Education, experience and existence: Engaging Dewey, Peirce and Heidegger, Abingdon: Routledge.

Quennerstedt, M. (2008) Exploring the relationship between physical activity and health - a salutogenic approach to physical education. Sport Education and Society, 13(3), 267-283. 
Quennerstedt, M., Almqvist, J. and Öhman, M. (2011). Keep your eye on the ball: Investigating artefacts-in-use in physical education. Interchange, 42, 287-305.

Sicilia-Camachoa, A. and Brown, D. (2008) Revisiting the paradigm shift from the versus to the non-versus notion of Mosston's Spectrum of teaching styles in physical education pedagogy: a critical pedagogical perspective. Physical Education and Sport Pedagogy, 13(1), 85-108.

Silcock, P. (2013) Should the Cambridge primary review be wedded to Vygotsky? Education 313, 41(3), 316-329.

Sloan S (2010) The continuing development of primary sector physical education: Working together to raise quality of provision. European Physical Education Review, 16, 267-281.

Smith, A. (2013) Primary school Physical Education and sports coaches: evidence from a study of School Sport Partnerships in north-west England. Sport Education and Society, 20(7), 872888.

Smith, W. (2016) Fundamental movement skills and fundamental games skills are complementary pairs and should be taught in complementary ways at all stages of skill development. Sport, Education and Society, 21(3), 431-442.

Sprake, A. and Walker, S. (2015) 'Blurred lines' the duty of physical education to establish a unified rationale, European Physical Education Review, 21(3), 394-406

STEPS PD (Steps Professional Development) (2004) Fundamental Movement Skills. Information Session Handout Booklet. Perth, Australia: Western Australian Minister for Education.

Stolz, S. (2014) The philosophy of physical education: A new perspective. Abingdon: Routledge.

Stolz, S. and Pill, S. (2016) A narrative approach to exploring TGfU-GS, sport Education and Society, 21(2), 239-261.

Svendsen, A. and Svendsen, J. (2016) Teacher or coach? How logics from the field of sports contribute to the construction of knowledge in physical education teacher education pedagogical discourse through educational texts. Sport, Education and Society, 21(5), 796-810.

Thorburn, M. and MacAllister, J. (2013) Dewey, interest and well-being: Prospects for improving the educational value of physical education. Quest, 65(4), 458-468.

Tinning, R. (2012) The idea of physical education: a memetic perspective. Physical Education and Sport Pedagogy, 17(2), 115-126.

Tinning, R. (2015) Commentary on research into learning in physical education: towards a mature field of knowledge. Sport, Education and Society, 20(5), 676-690.

Tsangaridou, N. (2014) Moving Towards Effective Physical Education Teacher Education for Generalist Primary Teachers: A View from Cyprus. Education 3-13, 44(6), 632-647.

van Beurden, E. Barnett, L., Zask, A. Dietrich, U. Brooks, L. and Beard, J. (2003) Can we skill and activate children through primary school physical education lessons? "Move it Groove it"-a collaborative health promotion intervention. Preventative Medicine, 36, 493-501. 
Walseth, K., Aartun, I. and Engelsrud, G. (2015) Girls' bodily activities in physical education: How current fitness and sport discourses influence girls' identity construction. Sport, Education and Society, i-first article, available at: http://dx.doi.org/10.1080/13573322.2015.1050370

Ward, G. (2012a) Examining Primary School Physical Education Coordinators' Pedagogical Content Knowledge of Games: Simply Playing At This? Education 3-13. 41(6), 562-585.

Ward, G. (2012b) They can't catch so what's the point in teaching them to play a game? In: Griggs, G. (Ed.) An Introduction to Primary Physical Education, London: Routledge

Ward, G. (2014) Learning movement culture: mapping the landscape between physical education and school sport. Sport Education and Society, 19(5), 569-604.

Ward, G. (2016) Knowing primary physical education movement culture. Unpublished: PhD by Publication Thesis. Available at: https://wlv.openrepository.com/wlv/bitstream/2436/615665/1/Ward_PhDThesis.pdf

Ward, G. and Griggs, G. (2011) Principles of play: a proposed framework towards a holistic overview of games in primary physical education, Education 3-13, 39(5), 499-516.

Ward, G. and Quennerstedt, M. (2014) Transactions in Primary Physical Education in the UK: A smorgasbord of looks-like-sport. Physical Education and Sport Pedagogy, 21(2), 137-152.

Ward, G. and Quennerstedt, M. (2015) Knowing in Primary Physical Education in the UK: Negotiating Movement Culture. Sport Education and Society, 20(5), 588-603.

Webb, L. Quennerstedt, M. and Öhman, M. (2008) Healthy bodies: the construction of body and health in physical education. Sport, Education and Society, 17(4), 353, 372.

Werner, P. (2004) Teaching children gymnastics, $2^{\text {nd }}$ edition. Leeds: Human Kinetics.

Whitehead, M. (2001) The concept of Physical Literacy.British Journal of Teaching Physical Education, 32(1), 127-138.

Whitehead, M. (2005) The moving self: The concept of physical literacy and the development of a sense of self. Paper presented at the IAPESGW, Edmonton, AB. available at:

http://www.physical-literacy.org.uk/edmonton2005.php [accessed: $20^{\text {th }}$ June, 2014]

Whitehead, M. (2007) Physical literacy: Philosophical considerations in relation to developing a sense of self, universality and propositional knowledge. Sport, Ethics and Philosophy, 1, 281298.

Whitehead, M. (2013) What is the education in physical education? In: S. Capel and M. Whitehead (Eds) Debates in Physical Education, Abingdon: Routledge, 22-36.

Wickman, P. and Östman, L. (2002) Learning as discourse change: A sociocultural mechanism. Science Education, 86, 601-623.

Wrench, A. and Garrett, R. (2015) Gender encounters: becoming teachers of physical education. Sport, Education and Society, i-first article, available at:

http://dx.doi.org/10.1080/13573322.2015.1032922 
Wright, J. (2000) Bodies, meanings and movement: A comparison of the language of a physical education lesson and a Feldenkrais movement class. Sport Education and Society, 5(1), 35-49. 